\title{
EXISTÊNCIA EMBURACADA NO CONTO “O BURACO” DE LUIZ VILELA
}

\author{
Rochele Moura Prass ${ }^{1}$ \\ Daniel Conte ${ }^{2}$ \\ Marinês Andrea Kunz ${ }^{3}$
}

\begin{abstract}
RESUMO: O conto O Buraco, da obra Tremor de Terra, publicada na década de 60 por Luiz Vilela, traz um narrador homodiegético, que, na vida adulta, repassa a infância, adolescência e juventude no que tange ao seu fascínio por um buraco. Este é aprofundado por suas próprias mãos até que, por fim, a personagem se transforma em um tatu, que passa a habitar esse espaço. O objetivo é analisar os sentidos engendrados pelo texto, a partir de questões que concernem à linguagem, imaginário e identidade. A justificativa diz respeito ao entendimento de que narrativas literárias proporcionam o (re)conhecimento da cultura de enunciadores e enunciatários dos textos desse gênero. As reflexões são embasadas nos postulados de Bosi (2000), Bachelard (1998) e Said (1993). Entende-se o narrador desse conto como um sujeito que se exila em um buraco, símbolo do pensamento subterrâneo, para transitar, pela metáfora da metamorfose, a uma nova identidade.
\end{abstract}

PALAVRAS-CHAVE: O Buraco; Literatura fantástica; Linguagem; Imaginário; Identidade.

\section{SELF-EXILED EXISTENCE ON THE SHORT STORY “O BURACO”, BY LUIZ VILELA}

ABSTRACT: The short story O Buraco, from the book Tremor de Terra, published in the 1960s by Luiz Vilela, features a homodiegetic narrator who, in his adulthood, reviews his childhood, adolescence and youth concerning his fascination with a hole. The hole is made deeper by his own hands until, eventually, the character changes into an armadillo, and begins to inhabit this space. The objective (of this article/ of this research) is to analyze the meanings created by the text, on matters regarding to language, the domain of imagination, and identity. The justification of the study is the understanding that literary narratives provide the recognition and knowledge of the culture of writers and readers in this text gender. The reflections are found on the ideas of Bosi (2000), Bachelard (1998) and Said (1993). The narrator of this short story is seen as a character who exiles to a hole, symbol of subterranean thought, to transition, through the metaphor of metamorphosis, to a new identity.

KEYWORDS: O Buraco; Fantastic literature; Language; Imaginary; Identity.

\footnotetext{
1 Mestra e doutoranda em Processos e Manifestações Culturais - Universidade Feevale. Bolsista Capes. E-mail: rocheleprass@gmail.com

2 Doutor em Literatura Brasileira, Portuguesa e Luso-africana. Professor Titular do PPG em Processos e Manifestações Culturais - Universidade Feevale. E-mail: danielconte@feevale.br

3 Doutora em Letras (PUCRS), professora e pesquisadora da UFPB. E-mail: marinesak5@gmail.com.
} 


\section{INTRODUÇÃO}

Em O Buraco, conto publicado na obra Tremor de Terra, de Luiz Vilela, na década de 1960, o narrador homodiegético conta, já na idade adulta, a estranha história de como se transformara em um tatu. Para tanto, adota uma estratégia narrativa linear, em que rememora a infância, a adolescência e o início de sua juventude, elucidando seu gosto por um buraco, que despertou ainda nos três primeiros anos de vida. Com o passar do tempo, o buraco e o fascínio do protagonista por esse brinquedo inusitado, se aprofundam. A expansão do buraco, cavado pelo narrador-personagem com as próprias mãos, está relacionada a suas relações socioafetivas, que se fragilizam no decorrer do tempo. Assim, esse sujeito, socialmente deslocado, relata o espanto dos outros mediante suas peculiaridades. Na infância, é incentivado por sua família a interagir com outras crianças. Ao crescer, amigos tentam resgatá-lo, via conselhos e conversas; outros, no entanto, simplesmente, dizem que siga seus instintos. Durante todo o percurso narrativo, evidenciam-se os cuidados e a aflição de sua mãe. Já na fase jovem adulta, o narrador aborda o sofrimento de sua noiva e o afastamento de todas as pessoas do seu entorno - exceto a mãe.

Por fim, o narrador-personagem, Zé (nome que só será conhecido em ponto avançado da trama), completa um processo metamórfico, em que se torna tatu, animal que, como se sabe, tem o hábito de viver no subterrâneo. No conto, os acontecimentos são tratados como verdadeiros, gerando estranhamento ao próprio narrador, demais personagens e ao leitor, o que se poderia classificar como uma narrativa fantástica (TODOROV, 2012). À guisa de localização do objeto de estudo no âmbito da arte literária, convém lembrar que as narrativas desse gênero não se pretendem reais, mas sim verossímeis (REIS, 2003). Nesse sentido, o texto, encerrando um universo ficcional entre suas primeiras e últimas linhas, aponta significações a serem completadas pelo leitor (RICOEUR, 1976).

É impossível, biologicamente, que tal metamorfose de fato ocorresse. Todavia, os fatos narrados em O Buraco correspondem a uma realidade apreensível pela via do metafórico. Assim, institui-se como objetivo deste escrito analisar os sentidos engendrados no referido conto, tendo como ponto de vista questões de linguagem, imaginário e identidade. Estas, observáveis na arte da escrita, aninham-se no seio da cultura e, via interpretação, a narrativa literária suscita o (re)conhecimento social, justificando a presente investigação, que parte da seguinte pergunta: como as imagens evocadas na narrativa se coadunam com o espaço da ação na representação da identidade metamórfica do narrador, gerando significações? Para tanto, adota-se um esquema metodológico de caráter qualitativo, indutivo e de viés exploratório, utilizando-se, como procedimento de pesquisa, o método bibliográfico (MARCONI; LAKATOS, 2003; GIL, 2008).

Os pressupostos teóricos que embasam as reflexões acerca do objeto deste artigo são os postulados de Bosi (2000) sobre a linguagem, bem como a capacidade de o verbal evocar imagens que gestam sentidos, como a metáfora. A Poética do Espaço, de Bachelard (1998), é a base para estabelecer as relações entre o cenário narrativo e o imaginário evocado no conto. A visão de Said (1993), no que tange ao conceito de exílio intelectual, é evocada na análise da identidade do narrador de O Buraco. Isso porque tal sujeito apresenta peculiaridades que levam a ponderações acerca das relações de alteridade entre ele e as demais personagens 
da trama. Ainda, vale ressaltar, esta análise propõe-se como um exercício interpretativo do referido objeto literário. Por essa razão, a Teoria da Interpretação, de Ricoeur (1976), subsidia o pensamento analítico hermenêutico.

\section{LINGUAGEM: A EXPERIÊNCIA DA IMAGEM PRECEDE A PALAVRA}

A arte literária, cuja matéria é a palavra escrita, engendra, pelos ditos e, também, pelos não-ditos, sentidos a serem interpretados pelo leitor, de modo que se trata de um processo que depende também das experiências de vida deste (RICOEUR, 1976). Desse modo, ainda que uma narrativa do gênero conto só se materialize pelo verbo, há uma questão latente. Seres humanos, cujos pensamentos, memória e existência são perpassados pela linguagem verbal, são atravessados por uma outra experiência: "A experiência da imagem, anterior à da palavra, vem enraizar-se no corpo. A imagem é afim à sensação visual. O ser vivo tem, a partir do olho, as formas do sol, do mar do céu. O perfil, a dimensão, a cor" (BOSI, 2000, p. 19).

No conto em análise, uma primeira imagem é evocada pela palavra "buraco". Está no título do texto, precedida do artigo definido. Percebe-se, desde logo, que não se trata de um buraco qualquer, mas sim de um que tem importância capital na narrativa: "Não sei como nem quando começou o buraco". A partir dessa ausência informativa, completa: "A lembrança mais antiga que tenho em mim coincide com a mais antiga que eu tenho dele: eu cavando-o com os dedos" (VILELA, 2017, p. 21).

Via linguagem, presentificando uma memória difusa no tempo da diegese, o narrador dá o tom onírico que se observará no decorrer do texto. Nota-se, nesse ponto, a coexistência de tempos abordada por Bosi (2000, p. 19), ao afirmar que "[...] o agora refaz o passado e convive com ele". O narrador relembra a sua relação com o buraco desde a infância. Nesse sentido, percorre suas memórias, reorganizando o seu jeito de ser e estar no mundo, narrando-se para se entender como um sujeito diferente, exótico em seu meio social, como observa Conte (2006):

É o buraco, esse labirinto, se transformará em abrigo seguro, em proteção completa à hostilização social, numa espécie de refúgio inviolável. É o único espaço em que criatura e criador, ou buraco e cavador, estarão total e plenamente distanciados dos elementos sociais que desestabilizam seus percursos. (p. 6).

Essa estratégia narrativa, na medida em que o protagonista se desnuda ao leitor, estabelece uma forte ligação com o receptor, promovendo uma cumplicidade emocional entre quem conta e quem lê. As limitações da memória humana são idênticas à limitação de uma arte que potencializa entendimentos na medida em que oferece lacunas a serem interpretadas pelo leitor. No que tange às memórias evocadas no ato de narrar, o leitor poderia se perguntar como um adulto teria tantos e minuciosos detalhes acerca da mais tenra infância. Assim, verifica-se, na diegese, um provável preenchimento da memória a partir da imaginação do adulto que, diante da sua intensa metamorfose, procura respostas sobre sua própria 
existência, constatando que sua estranheza, sua diferença, vem desde sempre. Essa interpretação emana do seguinte excerto:

Mas então ele já existia e não sei se era eu quem o havia começado, ou outra pessoa. Ou talvez estivesse ali por simples acidente da natureza. De qualquer modo é-me impossível saber como foi antes dessa lembrança, nem adiantaria perguntar às pessoas mais velhas que eu, que estivessem ao meu lado nesse tempo: como iriam lembrar-se disso? (VILELA, 2017, p. 21).

O enunciador, criando dúvidas sobre a memória, parece reforçar a imprecisão da origem do buraco. Ao fazê-lo, prenuncia que o escrutínio dessa gênese é desnecessário ou mesmo inútil diante do que está por vir. O que importa é que o buraco era um brinquedo infantil, exótico, mas que o aprazia desde os três anos de idade. Do mesmo modo, os motivos dessa bizarra preferência são aleatórios. Cavava simplesmente por gostar ou por tédio, analisa o narrador. Importante notar que o protagonista relata que, aos poucos, o buraco foi tomando forma. Ou seja, a consciência do formato, a imagem do objeto acompanha o amadurecimento desse sujeito, seja no tempo pretérito, seja no momento da rememoração. Todavia, é categórico, e um tanto contraditório no que tange à memória, ao afirmar:

Mas nessa época eu ainda não havia entrado nele, ficava apenas cavando-o. Mas já pensava nele como algo que pertencesse só a mim e a mais ninguém, e como algo secreto, embora ficasse ali no quintal à vista de todo mundo e as pessoas passassem ao seu lado e mesmo sobre ele; mas nem por isso deixava de ser meu e de ser secreto. (VILELA, 2017, p. 21).

A imagem do buraco é, assim, fascinante não apenas para o narrador que rememora. As palavras escolhidas para situar a história contada criam um desenho que tem a textura e o cheiro da terra, o esforço físico da escavação e a perspectiva do olhar de quem observa o objeto de fora. Ainda, evocam o mistério e atiçam a curiosidade que só poderá ser saciada nas últimas linhas do texto. Consoante Bosi (2000):

A imagem, mental ou inscrita, entretém com o visível uma dupla relação que os verbos aparecer e parecer ilustram cabalmente. O objeto dá-se, aparece, abre-se (latim: apparet) à visão, entrega-se a nós enquanto aparência: esta é a imago primordial que temos dele. Em seguida, com a reprodução da aparência, esta se parece com o que nos apareceu. Da aparência à parecença: momentos contíguos que a linguagem mantém próximos. (p. 20, grifos do autor).

A linguagem verbal ocupa espaço célebre na compleição do indivíduo e do seu meio cultural. Trata-se de uma aptidão biológica que, desde os primórdios da humanidade interage com a ação. Via verbalização, o indivíduo pode exteriorizar o pensamento, presentificar o objeto que não está diante dos olhos e, ainda, codificar experiências abstratas, como faz o narrador do conto de Vilela. Como lembra Bosi (2000, p. 33), “[...] A disposição dos 
sintagmas, sobre a qual assenta todo discurso, diz o quanto a linguagem humana é, ao mesmo tempo, sequência e estrutura, movimento e forma, curso e recorrência".

O narrador segue consolidando, sequencialmente, a importância do buraco na sua existência. Conta que cavava regularmente e que, já aos 11 anos de idade, ainda que não soubesse a razão, seguia cavando.

E então foi como se de repente eu o visse pela primeira vez - como se ele nunca tivesse existido antes desse dia, quando fiz quinze anos. Foi uma sensação empolgante, mas também assustadora, fiquei maravilhado e ao mesmo tempo com medo; na manhã desse dia eu estava alegre, mas de tarde não sabia se estava alegre ou triste, e de noite estava triste. De qualquer modo, uma coisa era certa: aquele buraco existia e era como se estivesse não ali fora mas dentro de mim. Eu podia ignorá-lo que ele estaria ali, continuaria ali como estava. (VILELA, 2017, p. 22-23).

As memórias do protagonista vão planeando o terreno em que o metafórico ganhará forma. Na adolescência, quando transita para uma outra fase da vida, ele tem consciência de que o buraco fez, faz e fará parte de sua existência. Ainda, no curso de um dia, experimenta as três emoções: a alegria matinal, infantil; as incertezas da tarde, adolescente; a tristeza noturna, o escuro que recobrirá a sua vida adulta. Nesse sentido, observa-se:

É necessário não perder de vista a distinção entre efeito imagético e procedimento semântico. Enquanto provém da intuição de semelhanças, a metáfora aparece como imagem; mas enquanto enlace linguístico de signos distantes, ela é atribuição, modo do discurso. (BOSI, 2000, p. 40).

Isso posto, procede-se à análise da imagem "buraco" e as significações suscitadas na trama narrativa.

\section{IMAGINÁRIO: O ESPAÇO DA AÇÃO NA CONVERGÊNCIA DE SENTIDOS}

Como visto, o buraco prenuncia a existência do narrador, estabelecendo o espaço central da narrativa. As ações psicológicas se desenrolam dentro e fora do buraco, mas sempre a partir dele. A casa da infância, espaço celebrado por Bachelard (1998) como recanto primeiro das memórias do sujeito, forja o corpo do narrador do conto em análise. Nesse sentido, buscando compreender a "intimidade do espaço interior", é preciso entender a casa, o espaço da ação, como uma unidade complexa "[...] tentando integrar todos os seus valores particulares num valor fundamental.” (BACHELARD, 1998, p. 23).

No conto de Vilela (2017), o buraco, cósmico ou físico, situa-se no quintal, enquanto a casa propriamente dita, o lugar dos inteiramente humanos, está à margem da narrativa. Importante notar que o texto presentifica outros espaços, mas como se fossem corpos celestes secundários, que apenas orbitam o buraco - ora o repelem; ora o compelem, mas sempre 
exercendo sua força gravitacional sobre o narrador. A rua, por exemplo, é o local em que Zé sente mais fortemente a sua incompatibilidade com o mundo exterior: "[...] quando saía à rua havia a risinhos de todos os lados: o tatu... o tatu... cochichavam, mas eu escutava como se estivessem gritando em meus ouvidos" (VILELA, 2017, p. 27). Todavia, o seu refúgio é o buraco, bom ou ruim, é nele que o narrador vive em plenitude: "todos os abrigos, todos os refúgios, todos os aposentos têm valores de onirismo consoante (BACHELARD, 1998, p. 25).

Evidentemente, no recorte narrativo, o buraco é o mote central do universo ficcional, mas é também um jogo que se ocupa de focar no habitat natural do fantástico ser metamórfico. Tal processo começa a tomar corpo exatamente nesse espaço, quando o narrador, em estado de devaneio, tentando suprimir o buraco da sua vida, acidentalmente cai nele:

No primeiro instante tive um pavor horrível, como se eu estivesse cara a cara com a coisa de que eu naquele dia da infância tivera a visão; ali estava ela, visível e invisível, palpável e imaterial. Meu primeiro impulso foi o de fugir, mas não fugi, porque fiquei paralisado, ou porque me dominei, não sei; mas não demorou o pavor foi sumindo e dando lugar a uma espécie de familiaridade com a coisa. Notei então o escuro de ali dentro, o frio das paredes. E isso que talvez fôsse o que me apavorou - de início, passou a me 'agradar - não exatamente a me agradar, mas a despertar minha curiosidade, a interessar-me. Ainda com um certo receio apalpei as paredes: eram frias, úmidas; cheguei até a cheirá-las: era o mesmo cheiro, mais forte, que eu já estava sentindo no ar ali dentro, cheiro de terra, um cheiro bom. Depois de alguns minutos a sensação de pavor havia desaparecido por completo, e eu sentia-me bem ali dentro, perfeitamente à vontade, como se fosse ali realmente o meu lugar, o meu habitat. (VILELA, 2017, p. 24).

Consoante Bachelard (1998, p. 26), “[...] a casa abriga o devaneio, a casa protege o sonhador, a casa nos permite sonhar em paz”. A verdadeira casa, centro do mundo, a imagem do universo (CHEVALIER; GHEERBRANT, 2019) desse narrador é, então, o buraco, como expressa verbalmente no excerto anterior. Todavia, não se trata, necessariamente, de um lugar físico, mas simbólico da origem das suas experiências subjetivas. Tanto é que o escrutínio desse espaço acompanha as estranhezas das sensações: o pavor que dá lugar ao familiar; o cheiro da terra que se torna agradável; o apalpar de paredes que imprime a dimensão do buraco. Dessa maneira, a imagem do buraco, na narrativa, já não é mais plana, como uma fotografia, e sim tridimensional. E a focalização já não é mais externa. Nos primeiros anos, percebia o seu entorno com o olhar voltado para o buraco - de cima para baixo; ao final, vê o mundo pelo ângulo subterrâneo - de baixo para cima. Conte (2006, p. 5) observa que ocorre com o personagem de Vilela um

[...] apagamento de elementos fundamentais de sua existência, [o que] o faz retirar-se e construir-se como Outro, [e] o faz ter a necessidade do sentido-calado. Como uma negação aos valores externos, aos caminhos embaralhados, ao abafamento dos ruídos e ao mascaramento das cores. A não vontade de brincar com os 
outros meninos, o ignorar os emocionados apelos de sua mãe, ou ainda, o gerar um proposital silenciamento para afastar Maria, sua noiva, denunciam seus anseios de isolamento assumidos no percurso metamorfósico.

É preciso levar em consideração que há uma contraposição, não explícita, entre o buraco e outros espaços. Desse modo, se, por um lado, há uma riqueza de sensações emanadas pelo peculiar abrigo do narrador, por outro, há imensa economia na descrição dos demais espaços. Do quintal, sabe-se pouco, mas é de onde escuta o apelo de sua noiva para que saísse do buraco “'Zé, você está?’ Eu não respondia. 'Zé, ô Zé, sou eu, Maria”” (VILELA, 2017, p. 26).

Acerca do seu quarto, o leitor sabe apenas que é de onde escuta o sinal que lhe permite escapar da casa e de sua mãe: "Nessa mesma noite, tão logo escutei o ressonar no quarto dela, saltei da cama e deslizando de quatro - já não conseguia mais ficar nas duas pernas - atravessei a casa, fui para o quintal e entrei no buraco" (VILELA, 2017, p. 28). Já transformado em tatu, a casa é novamente uma margem narrativa, quando o protagonista conta que, sentindo falta de ouvir a voz humana, abeirou a construção: "Isso aconteceu numa noite em que, levado por essa saudade, aproximei-me sorrateiramente da área lateral da casa, para onde dão as janelas da copa, e fiquei no escuro escutando" (VILELA, 2017, p. 30).

Enquanto efeito de sentido, o buraco frio e úmido, inegavelmente físico no universo da narrativa, desperta a sensação de um lugar sombrio, taciturno e mórbido. Nesse sentido, Bachelard (1998) discorre sobre imagens suscitadas pela edificação. Há uma psicologia da casa e ela se apresenta à memória de maneira polarizada em sua forma vertical.

A verticalidade é assegurada pela polaridade do porão e do sótão. As marcas dessa polaridade são tão profundas que abrem, de alguma forma, duas perspectivas muito diferentes para uma fenomenologia da imaginação. Com efeito, quase sem comentário, pode-se opor a racionalidade do telhado à irracionalidade do porão. O telhado revela imediatamente sua razão de ser: cobre o homem que tem medo infernava e do sol [...]. O próprio sonhador sonha racionalmente; para ele, o telhado pontiagudo corta as nuvens. Todos os pensamentos que se ligam ao telhado são claros. No sótão, vê-se, com prazer, a forte ossatura dos vigamentos. Participa-se da sólida geometria do carpinteiro. (BACHELARD, 1998, p. 36).

O porão de que fala Bachelard (1998) encontra, na narrativa de Vilela (2017), a extremidade subterrânea do buraco. Ambos estão no mesmo nível físico e, portanto, entende-se, são conceitualmente paralelos, ou seja, na mesma dimensão metafísica. Refugiando-se no seu porão imaginário, o buraco é ressignificado pela memória do narrador em trecho anterior à sua metamorfose:

Para conseguir, pois maior silêncio, e menos claridade, continuei cavando o buraco. As vêzes levava água e comida e passava o dia inteiro cavando-o. Quando cansava, parava de cavar e ficava lá à toa sem fazer nada, apenas sentindo o silêncio, o escuro, o cheiro da terra, aquêle cheiro que eu achava tão bom. (VILELA, 2017, p. 26). 
Assim como o buraco, o porão é obscuro, afronta a verticalidade da vida em sua pujança na cozinha, o lazer da sala, o repouso do quarto, a elevação dos pensamentos no sótão. A luz do quintal, onde verdejam plantas, dando espaço para extravasar as traquinagens infantis, com as quais o narrador pouco se identificava, não entra no porão - nem no buraco. Mas ele tem uma utilidade, diz Bachelard (1998, p. 36-37), que o classifica como "[...] o ser que participa das potências subterrâneas. Sonhando com ele, concordamos com a irracionalidade das profundezas."

Um buraco é, também, o destino final de seres humanos. Se os fantasmas habitam o porão, capaz de despertar calafrios (BACHELARD, 1998), numa cova repousam os corpos dos mortos. No conto, pode-se extrair da metamorfose completa o fenecer da criança, do adolescente e, por fim, do homem. Há, nesse sentido, mais um paralelo que se cria via interpretação: "[...] para êles eu estava realmente morto e o buraco era como se fôsse o meu túmulo" (VILELA, 2017, p. 29). Transmutado em tatu, o narrador tem a morte, simbólica, da forma humana e, entende-se, abraça completamente uma nova identidade.

\section{IDENTIDADE: NO BURACO DO EXÍLIO}

Tendo em vista que o tatu é um animal conhecido por habitar o subterrâneo e sair apenas à noite, passa-se à simbologia da metamorfose. Vale lembrar que o instinto primordial do narrador era o buraco e, então, a identidade de tatu surge, muito mais pelos olhos dos outros, até que o protagonista assuma, de fato, a sua nova forma.

As vêzes Mamãe me via cavando-o e dizia: "Meu filho, deixa êsse brinquedo, vai brincar na rua com os outros meninos." Mas às vêzes também via e não falava nada, não se importava, e de certo modo até parecia achar bom: "assim êle não vai pra longe”, ela dizia. Dizia também, para os outros: “Êle gosta de brincar sózinho.” Eu gostava também de brincar com os outros meninos na rua [...]; mas às vêzes deixava tudo isso e ia mexer com o buraco. (VILELA, 2017, p. 22).

Há, nesse sentido, uma identidade que começa a se formar na infância. O narrador, limitado nas muralhas da diegese e da sua própria memória, conta que sempre gostara de estar só no seu refúgio, ainda que, por vezes, a companhia humana fosse-lhe agradável: "Achava bom ficar ali sózinho, longe de todo mundo. Até que chegava um ponto em que também me cansava do buraco, sentia-me triste, e tinha vontade de voltar para as pessoas, conversar, falar, ouvir" (VILELA, 2017, p. 22).

Assim, ocorre uma fragmentação do sujeito, que culminará em sua metamorfose. Pode-se compreender esse híbrido pelo conceito de exilado intelectual de Said (2005). Primeiramente, o autor refere que o "O exílio é um dos destinos mais tristes [...]" e discorre acerca do mesmo na pré-modernidade, em que a deportação para outro país era um castigo, pois "[...] implicava não só anos de uma vida errante e incerta longe da família e dos lugares conhecidos, como também ficar numa espécie de estado proscrição [...]”. Ou seja, um sujeito em eterno deslocamento "[...] sempre em conflito com o que o rodeava, inconsolável em 
relação ao passado, amargo face ao presente e futuro". O autor lembra, ainda, que a ideia de exílio se associa ao "desprezo social e moral" (SAID, 2005, p. 51). Entre as profundezas do subterrâneo e a luz da rua, entre o isolamento e as pessoas por quem nutre afetos, o narrador de Vilela (2017) relata o seu imenso deslocamento social: "Mas chegava em casa e bastava ficar um pouco isolado dos outros e em silêncio que êle surgia dentro de mim, como uma serpente se erguendo no escuro" (VILELA, 2017, p. 23).

Mas é preciso lembrar que tal deslocamento, na paulatina negação de sua alteridade, acontecia mesmo quando estava entre pessoas. Nessa ordem, há a verbalização do constrangimento por sua identidade:

Houve ocasiões em que eu escondia dos outros o buraco, numa espécie de mêdo e pudor; ou, se me sentia muito triste por êle existir, mostrava-o para êles na esperança de que dissessem ou fizessem alguma coisa para diminuir minha tristeza; uns nem ligavam, outros davam conselhos, e alguns acabaram se oferecendo para me ajudar a tapá-lo; (VILELA, 2017, p. 23, grifos nossos).

Assim, nota-se que o meio social não fora o suficiente para curá-lo dessa estranheza, não havendo, como refere Said (2017), um espaço de negociação entre o sujeito exilado em seus singulares sentimentos e o que a sociedade espera dele: fechar o buraco existencial e viver, ainda que de maneira forjada, o caminho natural de um ser humano na sociedade. Trata-se, antes de tudo, de um sujeito incompreendido mesmo por aqueles que simplesmente não o importunavam: "disseram que eu era orgulhoso, que eu desprezava os outros ou que eu não me importava com êles, e até que os odiava. Quanta incompreensão. Havia também os que diziam: "Deixa, deixa êle; êle não tem jeito..." (VILELA, 2017, 23-24).

O narrador lembra que, por mais que tentasse, por mais que se importasse com a angústia alheia, sobretudo de sua mãe, não fora capaz de resistir ao chamamento metafórico do buraco. Assim, mostra-se como alguém que de fato tentou acomodar-se no lugar que a biologia e a sociedade reservaram para si. Na passagem do conto transcrita a seguir, é possível notar um momento de ruptura entre a identidade original e a nova. Se, por um lado, sofre com o que está deixando para trás, por outro, já não pertence mais a esse universo. Ainda, ressalta-se, a dor desse estado de transição é aprofundada pela incerteza do que está por vir.

Tive tanta pena dela êsse dia que prometi não voltar mais ao buraco. Mas a promessa durou pouco, eu não podia mais ficar fora do buraco, sentia-me desambientado, doente, tudo me feria, me incomodava, a luz do sol queimava meus olhos como se fosse fogo, os sons abalavam meus ouvidos [...] (VILELA, 2017, p. 26-27).

Said (2005, p. 52) analisa a existência do exilado como um "estado intermédio", em que o sujeito não está integralmente no novo habitat nem no antigo. No conto de Vilela (2017), observa-se que o narrador tem ambos os espaços físicos e metafóricos muito próximos e em consonância de significação subjetiva. A casa, e a família, estão a poucos metros 
do buraco, mas há um abismo simbólico entre os dois modos de vida. No que tange, especificamente, ao exilado, Said (2005, p. 52) explica: “[...] rodeado de semi-envolvimentos e semi-distanciamentos, nostálgico e sentimentalista, por um lado, imitador competente ou proscrito em segredo, por outro". Todavia, pondera, há espaço para adaptação, que pode ser traduzida num simples sobreviver, como faz o narrador do conto de Vilela (2017) durante a infância, adolescência e início da vida adulta.

Ainda consoante Said (2005, p. 54), “[...] o exílio, enquanto condição real, é também para o que me interessa uma condição metafórica." Em outras palavras, segue o autor, a condição de exilado pode ocorrer sem que seja necessário mudar de cidade, estado ou país. O exílio assume, então, a forma de um distanciamento entre a individualidade intelectual, na abordagem do teórico, e as ideias dominantes. No conto de Vilela (2017), pode-se associar tal conceito à já referida negação de alteridade. Nesse sentido, a identidade de tatu não é, exatamente, reconhecida pelo narrador, mas assumida a partir do sistemático deboche social:

[...] Riam sobretudo por causa de minha corcunda, que me viera à fôrça de cavar todo dia, e de meu rosto que fôra escurecendo e afinando. E é por isso que eu só andava com as mãos enfiadas nos bolsos, mesmo em casa, e na hora de usá-las para alguma coisa, como por exemplo para comer. (VILELA, 2017, p. 27).

Ressalta-se que é pela voz dos outros que a sua forma animal se solidifica. E isso tem reverberações no próprio corpo do sujeito, que, pouco a pouco, se transmuta afastando-se da anatomia humana. Retrai-se, esconde-se o quanto pode, mas não consegue desvencilhar-se do poderoso e dominante olhar externo e isso é determinante para mais um momento de sua transformação: "Num dêsses dias em que, ao sair à rua, ouvira as pessoas falando e rindo de mim, cheguei em casa tão deprimido que sem reparar comecei a andar de quatro" (VILELA, 2017, p. 27). Na sequência, nem mesmo o bolo de chocolate feito por sua mãe pode resgatá-lo da sua metamorfose:

Era doloroso, ela pressentia que era a última vez que me abraçava assim. De noite ela fêz um bôlo de chocolate, que era o bôlo de que eu mais gostava; tudo como se soubesse que era a última vez. Eu comi para que ela se sentisse feliz, mas já não achava mais graça em comer bôlo, e além do mais tinha de comer aos pedacinhos para passar na garganta e não me engasgar. (VILELA, 2017, p. 28, grifos nossos).

A partir desse momento, o homem assume integralmente a forma de tatu. A consciência da ruptura completa-se quando o narrador conta que, naquela noite, deixara a sua cama e fora viver no buraco. Tal qual um exilado que não consegue romper os laços identitários com a sua pátria, os laços com a mãe são firmes, afinal, ela continua procurando pelo filho, amando-o em sua nova forma e morada. Ao mesmo tempo, o narrador, refletindo sobre a sua identidade, constata que é: "[...] seu filho, porque nasci dela; mas o quê que 'ainda tenho de comum com ela? Sou um tatu, gosto é no escuro e no frio, sozinho; sou diferente dela, meu mundo é diferente, não tenho mais nada a ver com seu mundo, só a memória me liga a ela" (VILELA, 2017, p. 29). 
Com a noiva, acontece algo semelhante. Num primeiro momento, Maria segue procurando-o, buscando resgatá-lo do buraco. É inútil, pois o narrador conta que não a atende. Até que: “As visitas começaram a se espaçar. Maria não voltou mais. Só Mamãe vinha” (VILELA, 2017, p. 30). Todavia, refere, sente saudades de ouvir a voz humana e passa a rondar as margens da casa, apenas ouvindo conversas triviais que, no entanto, mantinham a memória da sua humanidade. Nesse sentido, como tatu, assume uma nova condição:

A condição de marginalidade, que pode parecer irresponsável e irreverente, liberta-nos da obrigação de proceder sempre com cautela, com medo de virar tudo do avesso, preocupados em não perturbar os companheiros, membros da mesma corporação. (SAID, 2005, p. 62).

O conto de Vilela (2017) encerra quando o narrador descobre que Maria havia casado com outro homem: "[...] senti uma pontada no coração e uma enorme tristeza” (p. 31). Entretanto, a noiva, que o abandona, tem razão, pensa o protagonista. Já não tinham mais nada em comum e amá-lo seria ridículo: "Mulher apaixonada por um tatu mata-se. Seria engraçado" (p. 31). Assim, o narrador assujeita-se. Não pode ser humano; não é inteiramente tatu; e, menos ainda, pode ser um pacífico híbrido de tatu e homem, solução que não parece possível neste universo ficcional.

\section{CONSIDERAÇÕES FINAIS}

O metafórico desse conto de Vilela (2017), característica do gênero fantástico, está longe de ser uma questão simples de resolver com uma mera conclusão que apontaria para este ou aquele significado estático. Pelo contrário, há muitos paralelos que podem ser extraídos do texto, ao sabor do auditório, como lembra Ricoeur (1976). Assim, é possível conjecturar sentidos tão particulares quanto a própria individualidade humana e fantasticamente atrelados ao universo cultural de quem recebe o texto.

Chama bastante atenção que a trama repassa toda infância e juventude da personagem, que se narra a partir de uma ótica adulta, quando sua metamorfose está completa. Na infância, apenas cavava, como uma excentricidade qualquer. Já na juventude, ao adentrar o buraco pela primeira vez, sente medo de algo tão familiar, mas que traz uma experiência inédita. A personagem reluta em seguir os seus instintos, a sua natureza e tem consciência de que esse modo de existir causa sofrimento aos que o amam. Assim, a velha luta de alteridades entra em cena. Transformar-se em um tatu, ser que habita o buraco, algo biologicamente inverossímil a um ser humano, é também uma metáfora de sua existência. Trata-se de um sujeito em descompasso com o seio familiar e social. E isso é evidenciado via discurso indireto livre, quando o narrador personagem, relatando a incompreensão dos amigos, mãe e noiva estabelece alteridades entre si e os humanos normais que o cercam.

Através do símbolo do buraco, cavado pelo narrador desde que a sua memória alcança a existência, o conto traz a ideia de um sujeito desajustado e incompreendido. O buraco, nesse sentido, é metáfora de uma existência sombria. Isso pode significar que sua consciên- 
cia humana é atravessada pelas vozes dos outros, fazendo com que ele se transforme em um híbrido proibido: um pouco homem adulto, um pouco criança que não entendia o significado do buraco e um pouco o que se transforma na narrativa: um tatu. Evocando imagens, como postulado por Bosi (2000), o narrador leva o simbólico a um lugar físico, um buraco frio, úmido, reservado aos que não têm mais direito à existência humana nos moldes que a sociedade reconhece como legítimos. O subterrâneo, tal qual evocado pelo pensamento de Bachelard (1998), é o espaço do lúgubre, do macabro, do inconfessável, do contraste com a vida social abrigada nos recantos mais nobres da casa. Com isso, o exílio do narrador, que recorre ao buraco para viver em um refúgio mais adequado socialmente à sua subjetividade, forja, também pela voz dos outros, a sua anatomia física e a sua identidade metamórfica, como são os exilados intelectuais de que fala Said (2005).

Os teóricos evocados e a metáfora do texto podem apontar que a metamorfose, o exílio e a identidade suprimida não estão tão longe assim da realidade do leitor. Basta observar como o pensamento dominante sistematicamente aniquila a alteridade, a identidade de quem nasceu para ser tatu e viver a sua plenitude híbrida em um meio cultural. Em alguns momentos, esses tatus podem ser aqueles que apenas pensam diferente no campo da política, das ideias e dos costumes. Em outros, podem ser os que sofrem de uma depressão, sugerida no texto, ou outro transtorno mental, que não vivem - nem precisam viver - na tão bem falada normalidade. Ainda, o narrador do conto pode ser um negro, secularmente deslocado entre o buraco da senzala e a casa grande, escravizado e agredido em razão do físico e espaço social que lhe foi destinado. Pode ser, também, uma identidade de gênero não permitida em uma sociedade heteronormativa. Por fim, cabe dizer que, levando as ações para um universo fantástico, o conto de Vilela (2017) abraça o impossível, em que tudo pode ser. Mas, sobretudo, enfatiza, pela perspectiva do narrador homodiegético, que ser tatu nesse universo cultural é deveras dolorido. 


\section{REFERÊNCIAS}

BACHELARD, Gaston. A casa. Do porão ao sótão. O sentido da cabana. In: A Poética do

Espaço. Tradução: Antonio de Pádua Danesi. São Paulo: Martins Fontes, 1998. p. 23-54.

BOSI, Alfredo. Imagem, Discurso. In: O ser e o tempo da poesia. São Paulo: Companhia das

Letras, 2000. p. 19-47.

CONTE, Daniel. Do Fazer-Se Em Silêncio: [ ]! Língua \& Literatura, [S.l.], v. 8, n. 12, p. 1-15, 2006.

CHEVALIER, Jean; GHEERBRANT, Alain. Dicionário de Símbolos. 33. ed. Rio de Janeiro: José Olympio, 2019.

GIL, Antonio Carlos. Métodos e Técnicas de Pesquisa Social. 6. ed. São Paulo: Atlas, 2008.

MARCONI; Marina de Andrade; LAKATOS, Eva Maria. Fundamentos da Metodologia Científica. 5. ed. São Paulo: Atlas, 2003.

REIS, Carlos. O Conhecimento da Literatura: introdução aos estudos literários. 1 ed. Porto Alegre: EDIPUCRS, 2003.

RICOEUR, Paul. Teoria da Interpretação: o discurso e o excesso de significação. Lisboa: Edições 70, 1976.

SAID, Edward W. Exílio intelectual: expatriados e marginais. In: Representações do

Intelectual: as conferências Reith de 1993. São Paulo: Companhia das Letras, 2005. p. 51-62.

TODOROV, Tzvetan. Introdução à Literatura Fantástica. São Paulo: Perspectiva, 2012.

VILELA, Luiz. O Buraco. In: Tremor de Terra. 10. ed. São Paulo; Rio de Janeiro: Record, 2017. p. 22-31. 
